\title{
Pengaruh Implementasi Kebijakan Pemeriksaan dan Forensik Digital terhadap Kualitas Pemeriksaan dan Keberhasilan Penerimaan Pajak
}

\author{
Luh Putu Dian Shavitri ${ }^{1}$ \\ Magister Manajemen \\ Universitas Pendidikan Nasional, \\ Indonesia
}

\author{
Gede Sri Darma² \\ Magister Manajemen \\ Universitas Pendidikan Nasional, \\ Indonesia
}

\begin{abstract}
Surel : shavitri.dian@gmail.com
\section{ABSTRAK}

Penelitian ini bertujuan untuk mendapatkan bukti empiris pengaruh implementasi kebijakan penentuan sasaran prioritas pemeriksaan, kebijakan buka rekening untuk kepentingan perpajakan dan forensik digital terhadap kualitas pemeriksaan dan penerimaan pajak hasil kegiatan pemeriksaan di Lingkungan Kanwil DJP Bali. Pendekatan yang digunakan adalah pendekatan kuantitatif dengan menggunakan metode purposive sampling dalam penentuan sampel dan metode Partial Least Square (PLS) sebagai teknik analisis data. Hasil penelitian mengindikasikan bahwa kebijakan penentuan sasaran prioritas pemeriksaan, kebijakan buka rekening dan forensik digital, memberikan pengaruh yang positif dan signifikan terhadap kualitas pemeriksaan dan penerimaan pajak hasil kegiatan pemeriksaan. Tax ratio indonesia yang masih tergolong rendah, menandakan masih banyak potensi pajak yang belum tergali.

Kata Kunci: Sasaran Prioritas Pemeriksaan; Buka Rekening; Forensik Digital; Kualitas Pemeriksaan; Penerimaan Pajak.
\end{abstract}

\section{Examining the Implementation of Taxation Audit Policy and Digital Forensic toward Tax Audit Quality and Tax Revenue Collection}

\begin{abstract}
This study aims to obtain empirical evidence on the influence of the implementation to determine the priority of Taxpayer to be audited policy, access to financial information for tax purposes policy and digital forensics toward tax audit quality and tax revenue in Bali Regional Office of Directorate General of Taxes. The approach that is used is quantitative approach using purposive sampling method in determining sample and Partial Least Square (PLS) method as data analysis technique. This study revealed that the implementation to determine the priority of Taxpayer to be audited policy, access to financial information for tax purposes policy and digital forensics has a positive and significant effect toward tax audit quality and tax revenue collection. Indonesia's tax ratio is still relatively low.
\end{abstract}

Keywords: $\quad$ Taxpayer Audit Priority; Bank Account Opening; Digital Forensics; Tax Audit Quality, Tax Revenue.

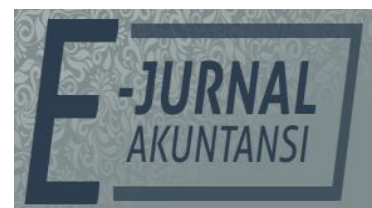

e-ISSN 2302-8556

Vol. 30 No. 10

Denpasar, Oktober 2020

Hal. 2682-2697

DOI:

10.24843/EJA.2020.v30.i10.p19

PENGUTIPAN:

Shavitri, L. P. D. \& Darma G. S. (2020). Pengaruh

Implementasi Kebijakan

Pemeriksaan dan Forensik

Digital terhadap Kualitas

Pemeriksaan dan

Keberhasilan Penerimaan

Pajak. E-Jurnal Akuntansi,

30(10), 1- 15

RIWAYAT ARTIKEL:

Artikel Masuk:

6 Mei 2020

Artikel Diterima:

26 Oktober 2020

Artikel dapat diakses : https://ojs.unud.ac.id/index.php/Akuntansi/index 


\section{PENDAHULUAN}

Dalam rangka melaksanakan pembangunan nasional yang bertujuan untuk memberikan kesejahteraan dan kemakmuran seluruh rakyat Indonesia secara adil dan merata, dibutuhkan pendanaan yang bersumber dari penerimaan negara terutama yang berasal dari pajak. Pajak merupakan sumber utama pendapatan negara. Domininasi penerimaan perpajakan mencapai $82,5 \%$ dalam APBN 2019 (Direktorat Penyusunan APBN, 2019). Penerimaan Pajak dari tahun ke tahun mengalami peningkatan yang signifikan dengan rata-rata pertumbuhan dalam 10 tahun terakhir mencapai $11.1 \%$, namun penerimaan ini masih lebih rendah dibandingkan potensi yang ada, diketahui dari tax ratio Indonesia yang berada dibawah $15 \%$ dalam 5 tahun terakhir, dengan rentang $10.7 \%$ sampai dengan 13.7\% (Direktorat Penyusunan APBN, 2019). Optimalisasi penerimaan pajak merupakan salah satu cara yang dapat dilakukan untuk menaikkan tax ratio Indonesia. Hal ini dapat dilakukan antara lain dengan meningkatkan kepatuhan dan pengawasan terhadap Wajib Pajak (Ministry of Fiscal Policy Agency, 2018).

Secara umum praktik agency theory dalam suatu perusahaan sering ditemui. Penghindaran pajak dilakukan oleh manajemen perusahaan karena terdapat konflik kepentingan dari para pemangku kepentingan yang ingin mendapatkan laba tinggi, sehingga pihak manajemen melakukan penghematan beban pajak (Lestari \& Nedya, 2019). Perlu adanya pengawasan dari pemerintah dan pentingnya pembaruan peraturan perpajakan dalam rangka meminimalkan praktik penghindaran pajak di perusahaan (Putra, Syah, \& Sriwedari, 2018).

MPengawasan terhadap Wajib Pajak dalam memenuhi kewajiban perpajakannya secara self-assessment (Republik Indonesia, 2007) melalui kegiatan pemeriksaan pajak merupakan hal yang esensial, karena merupakan salah satu bentuk alat penegakan hukum untuk menentukan keberhasilan penerimaan pajak, hal ini sejalan dengan hasil penelitian oleh Aspexsia (2018), Mebratu (2016), Palil \& Mustapha (2011), Asnawi (2013), namun berbeda dengan hasil penelitian oleh Modugu dan Anyaduba (2014), dimana pemeriksaan pajak belum berpengaruh terhadap pemenuhan pajak di Nigeria. Terkait kebijakan perpajakan, berdasarkan penelitian oleh (George \& Diavastis, 2015) diperoleh hubungan negatif antara undang-undang pajak dan pelacakan pelanggaran pajak, namun berdasarkan laporan OECD (2006) dan penelitian oleh D'Agosto, Manzo, Pisani, dan D'Arcangelo (2018), undang-undang hukum memegang peranan penting bagi kinerja pemeriksa pajak. Oleh karena itu, sejalan dengan reformasi birokrasi yang sedang dijalankan oleh Direktorat Jenderal Pajak dan kebutuhan akan penyempurnaan dalam kegiatan pemeriksaan, telah dilakukan penetapan terhadap beberapa kebijakan dalam rangka mendukung kegiatan pemeriksaan pajak yang berkualitas dengan bukti kompeten yang dapat diandalkan, diantaranya kebijakan mengenai penentuan sasaran prioritas pemeriksaan dengan kriteria yang telah ditetapkan melalui implementasi dari Surat Edaran Dirjen Pajak nomor 15 tahun 2018 tentang Kebijakan Pemeriksaan (Direktorat Jenderal Pajak, 2018), penetapan Perpu Nomor 1 Tahun 2017 Tentang Akses Informasi Keuangan Untuk Kepentingan Perpajakan, dimana Direktur Jenderal Pajak berwenang mendapatkan akses informasi keuangan untuk kepentingan perpajakan ke Lembaga Jasa Keuangan, Lembaga Jasa Keuangan 
Lainnya, dan/atau Entitas Lain, sehingga kegiatan Pemeriksaan dapat dilaksanakan dengan lebih optimal karena telah tersedianya akses yang luas bagi otoritas perpajakan untuk menerima dan memperoleh informasi keuangan bagi kepentingan perpajakan dalam pembentukan basis data perpajakan yang lebih kuat dan akurat(Pemerintah Republik Indonesia, 2017). Perkembangan teknologi informasi dan komunikasi mengakibatkan semakin banyak Wajib Pajak yang memanfaatkan teknologi digital, baik dalam menjalankan proses bisnisnya maupun dalam melakukan pengolahan data. Selain itu kehadiran Fintech juga merambah sektor keuangan dan memberikan dampak perubahan yang signifikan, FinTech hadir untuk menjawab permasalahan akses keuangan masyarakat pada lembaga keuangan konvensional(Darman, 2019). Dengan demikian upaya pengawasan dan penegakan hukum tidak mampu lagi menggunakan cara konvensional, sehingga dalam upaya penegakan hukum tersebut Direktorat Jenderal Pajak menetapkan Surat Edaran Direktur Jenderal Pajak nomor 36 tahun 2017 tentang Pedoman Forensik Digital untuk Kepentingan Perpajakan (Direktorat Jenderal Pajak, 2017).

Attribution Theory merupakan teori yang digunakan dalam pengembangan kerangka konseptual penelitian ini. Attribution Theory berfokus pada penyebab. Penyebab tersebut terlibat dalam menjelaskan hasil dan akhir dalam suatu proses seperti keberhasilan atau kegagalan. Secara umum, teori atribusi membedakan antara faktor-faktor penyebab, baik internal maupun eksternal terhadap perilaku individu (Försterling, 1988) yaitu, dimana dalam atribusi internal perilaku individu dianggap memegang kendali atau bertanggung jawab atas hasilnya, dan dalam atribusi eksternal, faktor situasional atau lingkungan dengan kontrol individu dianggap bertanggung jawab atas hasilnya (Murray \& Thomson, 2009). Berangkat dari teori tersebut, kesuksesan seorang Pemeriksa Pajak dalam rangka menghasilkan pemeriksaan yang berkualitas yang dapat memberikan kontribusi bagi penerimaan pajak hasil kegiatan pemeriksaan, dapat dipengaruhi oleh faktor internal yang berasal dari dalam diri Pemeriksa Pajak tersebut dan berdasarkan faktor eksternal yang berasal dari lingkungan atau situasional, salah satunya dukungan lingkungan kerja, implementasi dari kebijakan penentuan sasaran prioritas pemeriksaan, kebijakan buka rekening dan kebijakan pelaksanaan forensik digital dapat digolongkan sebagai faktor ekternal yang mampu mempengaruhi kesuksesan atau kegagalan atas hasil pemeriksaan yang dilakukan Pemeriksa Pajak, juga kaitannya dengan kesuksesan maupun kegagalan dalam pengumpulan penerimaan pajak.

Berdasarkan penjelasan teori dan research gap, penelitian ini ingin menganalisis dan memberikan bukti secara empiris mengenai pengaruh implementasi dari kebijakan penentuan sasaran prioritas pemeriksaan, kebijakan buka rekening untuk kepentingan perpajakan dan pelaksanaan forensik digital terhadap kualitas pemeriksaan dan penerimaan pajak hasil kegiatan pemeriksaan.

Semakin efektif pemilihan Wajib Pajak untuk diperiksa akan menimbulkan persepsi positif bagi Wajib Pajak, karena Wajib Pajak yang patuh mempunyai risiko lebih kecil untuk diperiksa dibandingkan dengan Wajib Pajak yang tidak patuh. Di sisi lain, pemeriksaan akan menjadi lebih efisien karena hanya dilakukan terhadap Wajib Pajak yang tidak patuh, hal ini senada dengan 
penelitian oleh Rotich, Kiprop \& Nzioki (2019) yang menemukan bahwa proses seleksi audit adalah faktor yang mempengaruhi efektivitas pemeriksaan pajak di Wilayah South Rift Valley Region. Penelitian lain dengan hasil serupa oleh Rahim, Topowijono \& Sudjana (2016) dimana diketahui bahwa kurang selektifnya dalam proses pemilihan atas Wajib Pajak yang diperiksa merupakan hambatan dan dapat mempengaruhi efektifitas pemeriksaan pajak. Asnawi (2013) memperoleh persepsi probabilitas audit terbukti berpengaruh pada peningkatan kepatuhan pajak. Sehingga hipotesis 1 yaitu Implementasi Kebijakan Penentuan Sasaran Prioritas Pemeriksaan berpengaruh positif terhadap Kualitas Pemeriksaan.

Kepatuhan Wajib Pajak dapat didefinisikan sebagai suatu keadaan dimana Wajib Pajak memenuhi semua kewajiban perpajakan sesuai dengan ketentuan yang berlaku, kebijakan akses informasi keuangan berpengaruh terhadap Perilaku Wajib Pajak dan berimplikasi terhadap kepatuhan Wajib Pajak (Sari \& Nugraha, 2018). Berdasarkan laporan OECD (2000) akses informasi bank dapat sangat meningkatkan kemampuan otoritas pajak untuk secara efektif melakukan verifikasi terhadap kewajiban pajak Wajib Pajak dan dalam rangka kegiatan penagihan kewajiban pajak. Informasi yang mungkin perlu diperoleh otoritas pajak dari bank untuk kasus-kasus tertentu adalah informasi tentang setoran dan penarikan. Sehingga hipotesis 2 yaitu Implementasi Kebijakan Buka Rekening berpengaruh positif terhadap Kualitas Pemeriksaan.

Forensik Digital berkaitan dengan kualitas pemeriksaan, dimana proses forensik digital memiliki kemampuan untuk dapat mempertajam akses pemeriksa dalam mendeteksi manipulasi laporan yang dilakukan dalam rangka penipuan pajak, seperti yang diperoleh berdasarkan hasil penelitian oleh Khersiat (2018) yang bertujuan untuk memberikan penekanan perlunya akuntan forensik untuk mendeteksi manipulasi laporan keuangan dan memerangi penipuan pajak di Yordania. Hasil penelitian senada dikemukakan oleh Irawan \& Maharani (2016) yang memperoleh hasil bahwa kualitas pemeriksaan pajak dipengaruhi oleh kemampuan pemeriksa dalam mengakses data Wajib Pajak baik internal maupun eksternal Direktorat Jenderal Pajak. Sehingga hipotesis 3 yaitu Forensik Digital berpengaruh positif terhadap Kualitas Pemeriksaan.

Dengan berkonsentrasi pada bidang yang memiliki risiko yang tinggi dan Wajib Pajak perorangan yang kemungkinan besar akan menghindari tanggung jawab perpajakan, audit dapat memberikan solusi secara signifikan atas ketidaktaatan pemenuhan kewajiban pajak sehingga mampu memberikan tambahan dalam penerimaan pajak OECD (2006). Hal ini senada dengan penelitian yang dikemukakan oleh Arifanda Purba (2012) dimana diketahi terdapat pola tertentu dari Wajib Pajak Badan yang dapat menghasilkan penerimaan pajak yang besar sesuai pemeriksaan yang dilakukan oleh Pemeriksa Pajak dan Alm, Blackwell \& McKee (2004) yang meneliti terkait aturan seleksi pemeriksaan Pajak Penjualan di AS dan dampaknya terhadap kepatuhan pajak yang dimana diketahui jika negara-negara mengikuti strategi seleksi pemeriksaan pajak yang sistematis dan mengetahui sumber-sumber ketidakpatuhan yang potensial, maka langkah tersebut juga dapat mengatasi beberapa potensi ketidakefisienan yang disebabkan oleh basis pajak yang sempit, dan memiliki potensi untuk meningkatkan pendapatan. Sehingga hipotesis 4 
yaitu implementasi Kebijakan Penentuan Sasaran Prioritas Pemeriksaan berpengaruh positif terhadap Penerimaan Pajak.

Penelitian oleh Nyanzi, Bbale \& Sendi (2018) mengungkap bahwa lembaga keuangan dan pasar keuangan memberikan dampak positif dan signifikan terhadap penerimaan pajak negara di Timur Afrika sehingga perhatian dapat ditujukan pada kebijakan akses ke lembaga keuangan. Berdasarkan penelitian oleh Okon (2018), akses dan pengembangan lembaga keuangan adalah penentu utama peningkatan pendapatan, otoritas pajak dapat memperoleh informasi berharga dari lembaga ini mengenai pendapatan dan aset para Wajib Pajak dimana mampu memberikan peningkatan pada penerimaan. Sehingga hipotesis 5 adalah Implementasi Kebijakan Buka Rekening berpengaruh positif terhadap Penerimaan Pajak.

Penghindaran pajak tentu berdampak bagi penerimaan. Al-Sharairi (2017) memperoleh hasil secara statistik, terdapat peran yang signifikan dari forensic accounting dalam membatasi praktik pengakuan pendapatan sebagai salah satu metode penghindaran pajak yang dilakukan oleh perusahaan industri Yordania. Nunn, McGuire, Whitcomb \& Jost (2006) dalam penelitiannya mendukung pelaksana forensic accounting sebagai upaya untuk mengurangi penghindaran pajak yang berdampak pada penerimaan, penelitian serupa oleh Ahmed Mahdi Hadi \& Ahmed Rahi Abed (2013) dimana diketahui faktor kegagalan dalam penerimaan pajak di Iraq salah satunya dipengaruhi oleh kurangnya sistem manajemen akuntansi forensik yang sesuai. Sehingga hipotesis 6 adalah Forensik Digital berpengaruh positif terhadap Penerimaan Pajak.

Kualitas pemeriksaan pajak memiliki pengaruh yang positif terhadap tingkat kepatuhan Wajib Pajak Badan, tingkat kepatuhan pajak akan tercermin pada menyempitnya tax gap (Setia, 2015). Berdasarkan penelitian oleh Hidayat \& Cheisviyanny (2013) diketahui kualitas penetapan pajak berpengaruh signifikan positif terhadap pencairan tunggakan pajak, Retnaningtyas Widuri, Devina \& Fransiska Marta (2019), dan Harelimana (2018) juga memperoleh bahwa pemeriksaan pajak yang dilakukan oleh otoritas perpajakan memiliki kontribusi yang signifikan dalam menyebabkan Wajib Pajak untuk memenuhi kewajiban pajak mereka. Engida \& Abera (2014) dari hasil penelitiannya mengungkapkan, frekuensi dan keakuratan pemeriksaan pajak dapat mendorong Wajib Pajak untuk lebih berhati-hati dalam melakukan pelaporan pajak, melakukan kesalahan pelaporan pajak dan tentu akan berdampak pada penerimaan pajak. Sehingga hipotesis 7 adalah Kualitas Pemeriksaan berpengaruh positif terhadap Penerimaan Pajak.

\section{METODE PENELITIAN}

Pendekatan yang digunakan pada penelitian ini adalah pendekatan kuantitatif. Penelitian ini dilaksanakan di Lingkungan Kanwil DJP Bali. Data primer dalam penelitian ini diperoleh dari pengisian kuesioner yang akan diisi oleh Pemeriksa Pajak di Lingkungan Kanwil DJP Bali. Populasi sasaran dalam penelitian ini adalah instruksi pemeriksaan yang terbit berdasarkan Daftar Sasaran Priotitas Pemeriksaan yang terbit per akhir Oktober 2019 yaitu sebanyak 260 instruksi pemeriksaan yang terbit. Adapun teknik sampling yang digunakan dalam penelitian ini adalah teknik non-probability sampling yaitu purposive sampling. 
Berdasarkan tabel penentuan jumlah sampel dari populasi tertentu yang dikembangkan oleh Isaac \& Michael (Sugiyono, 2013), untuk tingkat kesalahan 10\%, dengan jumlah populasi 260 diperlukan 133 jumlah sampel. Dalam penelitian ini digunakan 136 jumlah sampel. Jawaban setiap pertanyaan menggunakan skala semantik differensial 1-10 yang memiliki kategori dari yang sangat tidak setuju sampai dengan yang sangat setuju.

Variabel independen dalam penelitian ini adalah implementasi kebijakan penentuan sasaran prioritas pemeriksaan pajak (SSP), implementasi kebijakan buka rekening untuk kepentingan perpajakan (BUREK), dan pelaksanaan forensik digital (FD), sedangkan variabel dependen adalah kualitas pemeriksaan (KUAL) dan penerimaan pajak (PP). Teknik analisis data yang digunakan adalah Partial Least Square (PLS). Analisis data melalui PLS dalam penelitian ini dibagi menjadi dua bagian yaitu pengujian model (outer model) yang meliputi uji validitas dan uji reliabilitas dan evaluasi model struktural (inner model).

\section{HASIL DAN PEMBAHASAN}

Pada proses awal, sebelum masuk dalam pengukuran inner model (hubungan antar variabel laten), akan dilakukan pengujian terlebih dahulu terhadap reliabilitas meliputi uji Indicator Reliability dan Internal Consistency Reliability dan uji validitas meliputi uji validitas konvergen dan uji validitas diskriminan dari outer model-nya, yang akan dilakukan dengan menggunakan Aplikasi SmartPLS (v.3.2.8).

Uji Indicator reliability dapat diketahui melalui nilai outer loadings. Semakin tinggi nilai outer loadings artinya semakin tinggi korelasi antara variabel laten dan indikatornya atau semakin tinggi sebuah variabel laten dapat menjelaskan varian indikator dalam model pengukuran reflektif.

Tabel 1. Nilai Outer Loadings dari Tiap Indikator dalam Penelitian

\begin{tabular}{lccccc} 
& X1(SPP) & X2(BUREK) & X3 (FD) & Y1(KUAL) & Y2(PP) \\
\hline SPP1 & 0.897 & & & & \\
SPP2 & 0.845 & & & & \\
SPP3 & 0.760 & & & & \\
SPP4 & 0.877 & & & & \\
BUREK1 & & 0.807 & & & \\
BUREK2 & & 0.285 & & & \\
BUREK3 & & 0.811 & & & \\
BUREK4 & & 0.734 & & & \\
FD1 & & 0.708 & & \\
FD2 & & 0.772 & & \\
FD3 & & 0.811 & & \\
FD4 & & 0.830 & & 0.747 \\
KUAL1 & & & & 0.703 \\
KUAL2 & & & & 0.711 \\
KUAL3 & & & & 0.795 \\
KUAL4 & & & & \\
PP1 & & & & \\
PP2 & & & & \\
PP3 & & & & \\
PP4 & & & & & \\
\hline
\end{tabular}

Sumber: Data Penelitian, 2020 
Nilai outer loadings diharapkan lebih besar dari 0.7 , nilai minimum outer loadings yang dapat diterima dalam riset eksploratori adalah 0.4 (Ken KwongKay Wong, 2013). Jika nilai outer loadings < 0.4, indikator tersebut dapat dipertimbangkan untuk dieliminasi, namun dengan memperhatikan, eliminasi dari indikator tersebut dapat meningkatkan nilai composite reliability-nya (Henseler, Ringle, \& Sinkovics, 2009). Berdasarkan hasil pada Tabel 1, 19 indikator telah memenuhi indicator reliability dengan nilai $>0.4$, terdapat 1 indikator memiliki nilai outer loadings yang tidak memenuhi nilai minimum yang dapat diterima yaitu indikator BUREK2 dengan nilai outer loadings 0.285, nilai outer loadings tersebut $<0.4$, sehingga indikator BUREK2 tersebut dapat dipertimbangkan untuk dieliminasi. Setelah dilakukan eliminasi terhadap indikator BUREK2 diketahui bahwa terjadi peningkatan composite realibility yang lebih baik yaitu dari 0.771 menjadi 0.828 (Tabel 2 dan 3 ).

Tabel 2. Nilai Cronbach's Alpha dan rho_A

\begin{tabular}{lcccc}
\hline & \multicolumn{2}{c}{ Cronbach's Alpha $^{2}$} & \multicolumn{2}{c}{ rho_A } \\
\hline & Nilai sebelum & Nilai setelah & Nilai sebelum & Nilai setelah \\
\hline X1 (SPP) & 0.868 & 0.868 & 0.874 & 0.874 \\
X2 (BUREK) & 0.650 & 0.700 & 0.743 & 0.728 \\
X3 (FD) & 0.788 & 0.788 & 0.800 & 0.800 \\
Y1 (KUAL) & 0.719 & 0.719 & 0.726 & 0.726 \\
Y2 (PP) & 0.749 & 0.749 & 0.765 & 0.765 \\
\hline
\end{tabular}

Sumber: Data Penelitian, 2020

Pengukuran Internal Consistency Reliability dalam penelitian tradisional biasanya menggunakan nilai Cronbach's Alpha sebagai acuan, jika nilai $>0,80$ adalah skala yang baik, =0,70 adalah skala yang dapat diterima. Selain dengan Cronbach's Alpha, Internal Consistency Reliability dapat diukur menggunakan Composite Realibility, dibandingkan Cronbach's Alpha, Composite Reliability dipandang para peneliti dapat memberikan perkiraan reabilitas yang lebih baik karena memperhitungkan bahwa indikator memiliki beban yang berbeda. (G. David Garson, 2016). Untuk dapat dikatakan suatu item pernyataan reliabel, nilai Composite Reliability harus $>0,7$, dalam tahap awal penelitian (Henseler et al., 2009). Dari Tabel 2 dan Tabel 3, diketahui Internal Consistency Reliability dari tiap variabel laten X1(SPP), X2(BUREK), X3(FD), X4(KUAL), X5(PP), baik diukur melalui nilai Cronbach's Alpha maupun nilai Composite Realibility-nya telah berada $>0.7$, sehingga hasil uji menyatakan bahwa model telah memenuhi uji Internal Consistency Reliability.

Tabel 3. Nilai Composite Reliability dan Average Variance Extracted (AVE)

\begin{tabular}{lcccc}
\hline & \multicolumn{2}{c}{ Composite Reliability } & Average Variance Extracted (AVE) \\
\hline & Nilai sebelum & Nilai setelah & Nilai sebelum & Nilai setelah \\
\hline X1 (SPP) & 0.868 & 0.868 & 0.874 & 0.874 \\
X2 (BUREK) & 0.650 & 0.700 & 0.743 & 0.728 \\
X3 (FD) & 0.788 & 0.788 & 0.800 & 0.800 \\
Y1 (KUAL) & 0.719 & 0.719 & 0.726 & 0.726 \\
Y2 (PP) & 0.749 & 0.749 & 0.765 & 0.765 \\
\hline
\end{tabular}

Sumber: Data Penelitian, 2020 
Suatu instrument dikatakan valid apabila mampu mengukur apa yang diukur, karena suatu alat ukur yang valid mempunyai validitas yang tinggi. Terdapat dua jenis validitas dalam PLS SEM, yaitu validitas konvergen dan validitas diskriminan. Untuk menguji validitas konvergen setiap variabel laten, dapat dilakukan dengan menggunakan nilai rata-rata varian yang diekstraksi (Average Variance Extracted/AVE), nilai yang diharapkan $>0.5$ yang berarti sebuah variabel laten dapat menjelaskan lebih dari setengah varian indikatornya secara rata-rata (Ken Kwong-Kay Wong, 2013) dan (Henseler et al., 2009). Pada hasil penelitian di Tabel 3, nilai AVE telah $>0.5$, sehingga setiap variabel dalam penerlitian yaitu X1 (SPP), X2 (BUREK), X3 (FD), X4 (KUAL), X5 (PP), telah memenuhi uji validitas konvergen.

Validitas diskriminan digunakan untuk mengukur suatu variabel laten berbagi varian lebih dengan indikator yang mendasarinya daripada dengan variabel-variabel laten lainnya dalam model yang sama. Validitas Diskriminan dapat diukur dengan menggunakan kriteria Fornell-Larckell, jika akar kuadrat dari AVE di setiap variabel laten $>$ dari nilai korelasi di antara variabel laten lainnya maka dapat diartikan variabel laten tersebut telah memiliki validitas diskriminan yang baik (Ken Kwong-Kay Wong, 2013) dan (Hulland, 1999).

Tabel 4. Kriteria Fornell-Lacker

\begin{tabular}{lccccc}
\hline & X1 (SPP) & X2 (BUREK) & X3 (FD) & Y1 (KUAL) & Y2 (PP) \\
\hline X1 (SPP) & 0.846 & & & & \\
X2 (BUREK) & 0.328 & 0.785 & & & \\
X3 (FD) & 0.271 & 0.331 & 0.782 & & \\
Y1 (KUAL) & 0.429 & 0.443 & 0.418 & 0.735 & \\
Y2 (PP) & 0.487 & 0.659 & 0.514 & 0.663 & 0.743 \\
\hline
\end{tabular}

Sumber: Data Penelitian, 2020

Selain menurut kriteria Fornell-Larcker, validitas diskriminan juga dapat diukur menggunakan Cross Loading Factor. Cross loading menilai nilai loading pada konstruk yang dituju harus lebih besar dibandingkan dengan nilai loading dengan konstruk yang lain (Henseler et al., 2009).

Berdasarkan hasil yang diperoleh pada Tabel 4 dan 5, diketahui variabel laten telah memiliki validitas diskriminan yang baik berdasarkan kriteria FornellLarcker dan cross loading. Cara lain yang dapat digunakan untuk mengukur validitas diskriminan adalah dengan menggunakan Heterotrait-Monotrait (HTMT) ratio. HTMT ratio mampu mencapai tingkat spesifisitas dan sensitivitas yang lebih tinggi (97\%-99\%) dibandingkan Cross-Loadings (0,00\%) dan FornellLacker (20,82\%) (Henseler, Ringle, \& Sarstedt, 2014).

Jika nilai HTMT lebih tinggi dari ambang batas, dapat disimpulkan bahwa kurangnya validitas diskriminan (Henseler et al., 2009) dan (Ab Hamid, Sami, \& Mohmad Sidek, 2017). Menurut beberapa penelitian menyarankan nilai ambang batas 0.85 (Clark \& Watson, 2015) dan (Kline, 2015). Peneliti lain menyarankan nilai ambang batas 0.90 (Gold, Malhotra, \& Segars, 2001). 
Tabel 5. Kriteria Cross Loading

\begin{tabular}{lrcccc}
\hline & X1 $(\mathrm{SPP})$ & $\mathrm{X} 2(\mathrm{BUREK})$ & $\mathrm{X} 3(\mathrm{FD})$ & $\mathrm{Y} 1(\mathrm{KUAL})$ & $\mathrm{Y} 2(\mathrm{PP})$ \\
\hline SPP1 & 0.897 & 0.215 & 0.228 & 0.342 & 0.383 \\
SPP2 & 0.845 & 0.399 & 0.171 & 0.315 & 0.381 \\
SPP3 & 0.760 & 0.257 & 0.296 & 0.459 & 0.474 \\
SPP4 & 0.877 & 0.234 & 0.19 & 0.287 & 0.374 \\
BUREK1 & 0.313 & 0.813 & 0.357 & 0.411 & 0.655 \\
BUREK2 & 0.258 & 0.806 & 0.215 & 0.271 & 0.472 \\
BUREK3 & 0.175 & 0.735 & 0.163 & 0.339 & 0.363 \\
FD1 & 0.225 & 0.266 & 0.708 & 0.232 & 0.390 \\
FD2 & 0.269 & 0.253 & 0.772 & 0.256 & 0.382 \\
FD3 & 0.252 & 0.257 & 0.811 & 0.398 & 0.442 \\
FD4 & 0.115 & 0.264 & 0.830 & 0.393 & 0.391 \\
KUAL1 & 0.344 & 0.325 & 0.281 & 0.747 & 0.513 \\
KUAL2 & 0.402 & 0.376 & 0.301 & 0.764 & 0.571 \\
KUAL3 & 0.216 & 0.276 & 0.240 & 0.703 & 0.383 \\
KUAL4 & 0.267 & 0.310 & 0.402 & 0.725 & 0.453 \\
PP1 & 0.288 & 0.421 & 0.344 & 0.256 & 0.692 \\
PP2 & 0.268 & 0.308 & 0.356 & 0.275 & 0.711 \\
PP3 & 0.463 & 0.505 & 0.382 & 0.639 & 0.795 \\
PP4 & 0.378 & 0.633 & 0.434 & 0.636 & 0.770 \\
\hline Sumber: Data Pent & & & &
\end{tabular}

Sumber: Data Penelitian, 2020

Dalam penelitian ini, nilai ambang batas yang digunakan adalah 0.85. Berdasarkan Tabel 6, diketahui HTMT variabel<0.85, sehingga variabel laten telah memenuhi kriteria validitas diskriminan dengan menggunakan rasio HTMT dan dapat disimpulkan variabel laten dalam penelitian ini telah memiliki validitas diskriminan yang baik.

Tabel 6. HTMT Ratio

\begin{tabular}{lccccc}
\hline & X1 (SPP) & X2 (BUREK) & X3 (FD) & Y1 (KUAL) & Y2 (PP) \\
\hline X1 (SPP) & & & & & \\
X2 (BUREK) & 0.402 & & & & \\
X3 (FD) & 0.321 & 0.418 & & & \\
Y1 (KUAL) & 0.509 & 0.598 & 0.536 & & \\
Y2 (PP) & 0.559 & 0.821 & 0.653 & 0.798 & \\
\hline
\end{tabular}

Sumber: Data Penelitian, 2020

Analisa inner model dilakukan untuk memastikan bahwa model struktural yang dibangun robust dan akurat, hal ini dilakukan setelah memastikan pengujian outer model telah reliabel dan valid (Henseler et al., 2009). Uji koefisien jalur merupakan nilai besarnya hubungan atau pengaruh variabel eksogen terhadap veriabel endogen, dilakukan menggunakan prosedur Bootrapping (Henseler et al., 2009). Dalam bootstrap, sejumlah besar sampel diambil dari sampel asli dengan dilakukan penggantian. Penggantian dilakukan dengan mengambil secara acak melalui populasi sampel, sampel yang telah diambil memiliki peluang untuk diambil lebih dari satu kali atau bahkan tidak ikut terambil sama sekali dalam satu kali tahap obeservasi (Hair Jr, Hult, Ringle, \& Sarstedt, 2017). Uji koefisien jalur pada penelitian ini menggunakan uji T (2tailed) dengan tingkat signifikansi 5\% dengan 500 subsample, dimana koefisien jalur dinilai signifikan bila nilai tstatistik $>$ tkritis yaitu 1.960 dan nilai $\mathrm{P}<0,05$. Nilai koefisien jalur dari hasil penelitian diperoleh sebagai berikut. 
Tabel 7. Path Coefficients

\begin{tabular}{lcclll}
\hline & $(\mathrm{O})$ & $(\mathrm{M})$ & $(\mathrm{STDEV})$ & T Statistics & P Values \\
\hline X1 (SPP) -> Y1 (KUAL) & 0.272 & 0.254 & 0.085 & 3.204 & 0.001 \\
X1 (SPP) -> Y2 (PP) & 0.160 & 0.161 & 0.054 & 2.935 & 0.003 \\
X2 (BUREK) -> Y1 (KUAL) & 0.269 & 0.271 & 0.065 & 4.157 & 0.000 \\
X2 (BUREK) -> Y2 (PP) & 0.391 & 0.391 & 0.066 & 5.961 & 0.000 \\
X3 (FD) -> Y1 (KUAL) & 0.256 & 0.281 & 0.108 & 2.373 & 0.018 \\
X3 (FD) -> Y2 (PP) & 0.200 & 0.194 & 0.062 & 3.214 & 0.001 \\
Y1 (KUAL) -> Y2 (PP) & 0.338 & 0.339 & 0.064 & 5.312 & 0.000 \\
\hline
\end{tabular}

Sumber: Data Penelitian, 2020

Nilai R2 adalah koefisien determinasi pada variabel endogen. Dalam penelitian ini terdapat dua variabel endogen yang memiliki nilai R2, yaitu (Y1) KUAL dan Y2 (PP). Berdasarkan hasil penelitian diperoleh R2 (Y1) KUAL=0.343 atau 34.3\% (Y1) KUAL dipengaruhi oleh variabel yang ada dalam model dan R2 (Y2) PP $=0.663$ atau $66.3 \% \mathrm{Y} 2(\mathrm{PP})$ dipengaruhi oleh variabel yang ada dalam model. Menurut Chin (1998), nilai R2 sebesar 0.67 (kuat), 0.33 (moderat) dan 0.19 (lemah) sehingga kedua nilai R2 dalam penelitian in dikategorikan moderat.

Nilai f2 digunakan untuk mengukur perubahan dalam koefisien determinasi ketika variabel eksogen tertentu dihilangkan dari model, untuk mengevaluasi dampak substantif variabel eksogen tersebut terhadap variabel endogen. Nilai f2 = R2included - R2excluded / 1-R2included. Nilai R2included merupakan nilai $\mathrm{R} 2$ variabel dependen ketika semua variabel masuk ke dalam model. Nilai R2excluded merupakan nilai R2 variabel endogen ketika variabel eksogen yang ingin diketahui effect size-nya dikeluarkan dari model (Hair Jr et al., 2017). Nilai f2 =0,02 (lemah), f2 =0,15 (cukup) dan $\mathrm{f} 2=0,35$ (kuat) pengaruh variabel eksogen terhadap variabel endogennya (Cohen, 1988). Dalam penelitian ini, X1 $(\mathrm{SSP})=0.06$ (pengaruh lemah terhadap Y2 $(\mathrm{PP})), \mathrm{X} 2(\mathrm{BUREK})=0.345$ (pengaruh cukup terhadap Y2 (PP), X3 (FD) $=0.09$ (pengaruh lemah terhadap $\mathrm{Y} 2$ $(\mathrm{PP}))$ dan Y1 (KUAL) $=0.223$ (pengaruh cukup terhadap Y2(PP))

Evaluasi prediction relevance (Q2) atau Stone-Geisser's Value, dilakukan untuk mengetahui kapabilitas prediksi dengan prosedur blindfolding pada bagian construct cross validated redudancy. Prosedur blindfolding dalah teknik resampling yang secara sistematis menghapus dan memprediksi setiap titik data dari indikator dalam model pengukuran reflektif dari variabel endogen (Hair Jr et al., 2017) dan (G. David Garson, 2016). Nilai Q2 > 0 menunjukkan model memiliki predictive relevance, sebaliknya nilai $\mathrm{Q} 2<0$ menunjukkan model kurang memiliki predictive relevance. Rentang nilai $\mathrm{Q} 2=0<\mathrm{Q}<1$, dimana semakin mendekati 1 berarti model semakin baik (Henseler et al., 2009). Dari hasil penghitungan, diketahui nilai Q2 konstruk endogen $\mathrm{Y} 2(\mathrm{PP})=0,313$, dimana Q2 $>0$, maka model tersebut sudah memenuhi relevansi prediktif untuk konstruk endogen Y2 (PP). Nilai Q2 variabel endogen Y1 (SSP) $=0.162$ dimana Q2 > 0 , maka model tersebut telah memenuhi relevansi prediktif untuk variabel endogen Y1 (SSP). 
Jika dianalogikan dengan pengaruh $\mathrm{f} 2$, dampak relatif dari relevansi prediktif dapat dinilai dengan alat ukur q2, nilai 0.02, 0.15, dan 0.35 mengungkapkan relevansi prediksi kecil, sedang, dan besar dari variabel laten tertentu, dengan demikian menjelaskan sifat endogen dari variabel laten yang dievaluasi (Henseler et al., 2009). Nilai dari besaran efek q2 dapat dihitung dengan terlebih dahulu mengetahui nilai dari Q2. Rumus perhitungan q2 adalah $=\mathrm{Q} 2$ included-Q2excluded/1-Q2included. Q2 predictive relevance included adalah nilai Q2 dimana semua variabel masuk ke dalam model. Nilai Q2 predictive relevance excluded adalah nilai dari konstruk endogen ketika variabel yang ingin diketahui besaran efeknya dihilangkan. Nilai Q2 predictive relevance included dapat diketahui dari Q2 konstruk endogen (Hair Jr et al., 2017). Dalam penelitian ini Nilai Q2 predictive relevance included adalah nilai Q2 dari konstruk endogen yaitu $\mathrm{Y} 2(\mathrm{PP})$, sedangkan $\mathrm{Q} 2$ predictive relevance excluded adalah nilai Q2 konstruk endogen Y2 (PP) ketika variabel yang ingin diketahui effect size-nya dihilangkan dari model.

Tabel 8. Besaran Efek q2

\begin{tabular}{lcccc}
\hline \multicolumn{1}{c}{ Variabel } & $\begin{array}{c}\mathrm{Q}^{2} \text { predictive } \\
\text { relevance included }\end{array}$ & $\begin{array}{c}Q^{2} \text { predictive relevance } \\
\text { excluded }\end{array}$ & $q^{2}$ & Kategori \\
\hline X1 (SPP) & & 0.304 & 0.01 & lemah \\
X2 (BUREK) & 0.313 & 0.257 & 0.08 & lemah \\
X3 (FD) & & 0.298 & 0.02 & lemah \\
Y1 (KUAL) & & 0.284 & 0.04 & lemah \\
\hline
\end{tabular}

Sumber: Data Penelitian, 2020

Dari Tabel 8, diketahui besaran efek q2 berada dalam kategori lemah dimana tidak menunjukkan perubahan pengaruh yang signifikan baik ketika variabel tersebut ada dalam model maupun dikeluarkan dari model, dimana dapat diartikan konstruk eksogen dalam penelitian ini memiliki prediktif relevansi yang rendah terhadap konstruk endogennya.

Hipotesis pertama (H1) menyatakan variabel X1(SPP) berpengaruh positif signifikan terhadap Y1 (KUAL). Nilai tstatistik dari X1(SPP)->Y1(KUAL) $=3.204$ dan nilai $\mathrm{P}=0.001$. tstatistik (3.204) $>$ tkritis (1.960) dan $\mathrm{P}=0.001<0.05$, sehingga dapat dinyatakan pengaruh Implementasi Kebijakan Penentuan Sasaran Prioritas Pemeriksaan (X1) terhadap Kualitas Hasil Pemeriksaan Pajak (Y1) adalah positif signifikan. Oleh karena itu H1 dinyatakan terbukti.

Hipotesis kedua (H2) menyatakan variabel X2(BUREK) berpengaruh positif signifikan terhadap Y1 (KUAL). Nilai tstatistik dari X2(BUREK)-> Y1 $($ KUAL) $=4.157$ dan nilai $\mathrm{P}=0.000$. tstatistik $(4.157)>$ tkritis (1.960) dan $\mathrm{P}=0.000<0.05$, sehingga dapat dinyatakan pengaruh Implementasi Kebijakan Buka Rekening (X2) terhadap Kualitas Pemeriksaan Pajak (Y1) adalah positif signifikan. Oleh karena itu $\mathrm{H} 2$ dinyatakan terbukti.

Hipotesis ketiga (H3) menyatakan variabel X3 (FD) berpengaruh positif signifikan terhadap Y1 (KUAL). Nilai tstatistik dari X3 (FD)-> Y1 (KUAL) $=2.373$ dan nilai $\mathrm{P}=0.018$. tstatistik (2.373) $>$ tkritis $(1.960)$ dan $\mathrm{P} 0.018<0.05$, sehingga dapat dinyatakan pengaruh Pelaksanaa Forensik Digital (X3) terhadap Kualitas Pemeriksaan Pajak (Y1) adalah positif signifikan. Oleh karena itu hipotesis 3 dinyatakan terbukti. 
Hipotesis keempat (H4) menyatakan variabel X1 (SPP) berpengaruh positif signifikan terhadap Y2 (PP). Nilai tstatistik dari X1 (SSP)->Y2 (PP) $=2.935$ dan nilai $\mathrm{P}=0.003$. tstatistik $(2.935)>(1.960)$ dan $\mathrm{P}=0.003<0.05$, sehingga dapat dinyatakan pengaruh Implementasi Kebijakan Penentuan Sasaran Prioritas Pemeriksaan (X1) terhadap Penerimaan Pajak (Y2) adalah positif signifikan. Oleh karena itu hipotesis 4 dinyatakan terbukti.

Hipotesis kelima (H5) menyatakan variabel X2(BUREK) berpengaruh positif signifikan terhadap Y2 (PP). Nilai tstatistik dari X2(BUREK)->Y2 $(\mathrm{PP})=5.961$ dan nilai $\mathrm{P}=0.000$. tstatistik $(5.961)>(1.960)$ dan $\mathrm{P}=0.000<0.05$, sehingga dapat dinyatakan pengaruh Implementasi Kebijakan Buka Rekening (X2) terhadap Penerimaan Pajak (Y2) adalah positif signifikan. Oleh karena itu hipotesis 5 dinyatakan terbukti.

Hipotesis keenam (H6) menyatakan variabel X3(FD) berpengaruh positif signifikan terhadap Y2 (PP). Nilai tstatistik dari $\mathrm{X} 2(\mathrm{FD})->\mathrm{Y} 2(\mathrm{PP})=3.214$ dan nilai $\mathrm{P}=0.001$. tstatistik (3.214) $>1.960$ dan $\mathrm{P}=0.001<0.05$, sehingga dapat dinyatakan pengaruh Pelaksanaan Forensik Digital (X3) terhadap Penerimaan Pajak (Y2) adalah positif signifikan. Oleh karena itu hipotesis 6 dinyatakan terbukti.

Hipotesis ketujuh (H7) menyatakan variabel Y1 (KUAL) berpengaruh positif signifikan terhadap Y2 (PP). Nilai tstatistik dari Y1 (KUAL)->Y2 (PP) = 5.312 dan $\mathrm{P}=0.000$. tstatistik (5.312) $>1.960$ (standar) dan $\mathrm{P}=0.000<0.05$, sehingga dapat dinyatakan pengaruh Kualitas Pemeriksaan (Y1) terhadap Penerimaan Pajak (Y2) adalah positif signifikan. Oleh karena itu hipotesis 7 dinyatakan terbukti.

Temuan ini memperjelas konsep Attribution Theory, dimana terdapat penyebab yang berasal dari faktor eksternal yaitu kebijakan penentuan prioritas pemeriksaan, kebijakan buka rekening dan forensik digital yang mempengaruhi secara positif dan signifikan atas keberhasilan pemeriksaan dan penerimaan pajak.

Tax ratio Indonesia yang masih tergolong rendah, menandakan masih banyak potensi pajak yang belum tergali, sehingga hasil penelitian ini diharapkan dapat memberikan kontribusi berarti bagi otoritas pajak dan pihak terkait lainnya, agar dapat mengimplementasikan strategi yang sesuai untuk meningkatkan kualitas pemeriksaan dan tentunya penerimaan pajak hasil kegiatan pemeriksaan. Kebijakan penentuan Wajib Pajak untuk diperiksa agar memberikan penekanan terhadap strategi dan panduan yang sistematis untuk mengetahui sumber-sumber ketidakpatuhan yang potensial, serta memberikan perhatian terhadap penguatan basis data perpajakan. Selain itu, perlu dilakukan pembaruan kebijakan yang terus-menerus dalam rangka menjamin kemudahan, kecepatan dan ketepatan akses data perbankan untuk kepentingan perpajakan dan peningkatan kapabilitas dalam pengenalan, pencarian, perolehan dan dokumentasi data Wajib Pajak dengan membekali tiap pemeriksa pajak dengan keahlian forensik digital.

\section{SIMPULAN}

Berdasarkan temuan penelitian diketahui terdapat pengaruh implementasi kebijakan penentuan sasaran prioritas pemeriksaan, implementasi kebijakan buka rekening dan pelaksanaan forensik digital terhadap kualitas pemeriksaan 
dan penerimaan pajak hasil kegiatan pemeriksaan dan kualitas pemeriksaan juga memberikan pengaruh terhadap penerimaan hasil kegiatan pemeriksaan dalam lingkup Kanwil DJP Bali.

Dari hasil penelitian yang telah diuraikan, maka dapat disarankan bagi penelitian selanjutnya agar pengaruh pemilihan Wajib Pajak untuk diperiksa, kebijakan buka rekening dan forensik digital dapat dilakukan terhadap lebih banyak kegiatan pemeriksaan dan melibatkan lebih banyak responden, karena tiap responden memiliki pengalaman yang berbeda dalam implementasi kebijakan perpajakan tersebut. Pada penelitian selanjutnya juga dapat dilakukan penambahan variabel terkait faktor internal bagi pemeriksa pajak yang dapat mempengaruhi kualitas pemeriksaan dan penerimaan pajak.

\section{REFERENSI}

Ab Hamid, M. R., Sami, W., \& Mohmad Sidek, M. H. (2017). Discriminant Validity Assessment: Use of Fornell \& Larcker criterion versus HTMT Criterion. Journal of Physics: Conference Series, 890(1). https:// doi.org/10.1088/1742-6596/890/1/012163

Ahmed Mahdi Hadi, Ahmed Rahi Abed, H. O. K. (2013). The Role of Forensic Accounting. Academy of Accounting and Financial Studies Journal, 4(54), 1-10. Retrieved from http://en.cnki.com.cn/Article_en/CJFDTotalJJSY201304054.htm

Al-Sharairi, M. E. (2017). The Role of Forensic Accounting in Limiting Tax Evasion in the Jordanian Public Industrial Shareholding Companies through the Perspective of Jordanian Auditors. International Journal of Economics and Finance, 10(1), 233. https:/ / doi.org/10.5539/ijef.v10n1p233

Arifanda Purba. (2012). Analisis hasil pemeriksaan pajak tahun 2008-2011 untuk menentukan Pola profil wajib pajak badan yang potensial di Kantor Pelayanan Pajak Pratama Jakarta Palmerah. Retrieved from http:/ / lib.ui.ac.id/detail?id=20313723\&lokasi=lokal

Asnawi, M. (2013). The Impact of Audit Rate, Perceived Probability of Audit on Tax Compliance Decision: A Laboratory Experiment Study). Jurnal Ekonomi $\mathcal{E}$ Bisnis Indonesia (Fakultas Ekonomi Dan Bisnis Universitas Gadjah Mada), 28(2), 286-301. https:/ / doi.org/10.22146/jieb.29763

Aspexsia, A. P. (2018). Pengaruh Pemeriksaan Pajak Terhadap Kepatuhan Wajib Pajak di Indonesia (Universitas Gadjah Mada). Retrieved from http://etd.repository.ugm.ac.id/index.php?mod=penelitian_detail\&sub=Pe nelitianDetail\&act $=$ view\&typ=html\&buku_id=164099\&obyek_id=4

Chin, W. W. (1998). The partial least squares approach for structural equation modeling. In Methodology for Business and Management. Modern methods for business research. (pp. 295-336). Retrieved from https://www.researchgate.net/publication/311766005_The_Partial_Least_S quares_Approach_to_Structural_Equation_Modeling

Cohen, J. (1988). Statistical Power Analysis for the Behavioral Sciences (2nd ed.). New York: Lawrence Erlbaum Associates, Publishers.

D'Agosto, E., Manzo, M., Pisani, S., \& D'Arcangelo, F. M. (2018). The Effect of Audit Activity on Tax Declaration: Evidence on Small Businesses in Italy. Public 
https:// doi.org/10.1177/1091142117698035

Darman. (2019). Financial Technology (FinTech): Karakteristik dan Kualitas Pinjaman pada Peer to Peer Lending di Indonesia. Jurnal Manajemen Teknologi, 18(2), 130-137. https:/ / doi.org/10.12695/jmt.2019.18.2.4

Direktorat Jenderal Pajak. (2017). SE-36/PJ/2017 tentang Pedoman Forensik Digital Untuk Kepentingan Pajak. Retrieved from https://www.ortax.org/ortax/?mod=aturan\&hlm=6\&page=show\&id=1639 1

Direktorat Jenderal Pajak. (2018). SE-15/PJ/2018 Tentang Kebijakan Pemeriksaan. Retrieved from https:/ / www.ortax.org/ ortax/?mod=aturan\&hlm=1\&page=show\&id=1653 1

Direktorat Penyusunan APBN. (2019). Informasi APBN 2019. Kementerian Keuangan Republik Indonesia, 61. Retrieved from https://www.kemenkeu.go.id/apbn2019

Engida, T., \& Abera, G. (2014). Factors influencing Taxpayers' Compliance with Tax System: An Empirical Study of Mekelle City, Ethiopia. E-Journal of Tax Research. The University of New South Wales. Sydney, vol 12, $433 \square 452$. Retrieved from https://www.business.unsw.edu.au/researchsite/publications-site/ ejournaloftaxresearchsite/Documents/07_EngidaBaisa_FactorsInfluencingTaxpayersCompliance. pdf

Försterling, F. (1988). Attribution theory in clinical psychology. In J. Harrow (Ed.), Attribution theory in clinical psychology. Oxford, England: John Wiley \& Sons.

G. David Garson. (2016). Partial Least Squares (PLS-SEM):Regression E Structural Equation Models. Retrieved from https://www.smartpls.com/resources/ebook_on_pls-sem.pdf

George, D. S., \& Diavastis, I. (2015). Tax audit effectiveness in Greek firms: Tax auditors perceptions. Journal of Accounting and Taxation, 7(7), 123-130. https:// doi.org/10.5897/jat2015.0186

Gold, A. H., Malhotra, A., \& Segars, A. H. (2001). Knowledge management: An organizational capabilities perspective. Journal of Management Information Systems, 18(1), 185-214. https:/ / doi.org/10.1080/07421222.2001.11045669

Gupta, M., \& Nagadevara, V. (2007). Audit Selection Strategy for Improving Tax Compliance - Application of Data Mining Techniques. Retrieved from https://www.researchgate.net/publication/254667082_Audit_Selection_Str ategy_for_Improving_Tax_Compliance__Application_of_Data_Mining_Techniques

Hair Jr, J. F., Hult, G. T. M., Ringle, C., \& Sarstedt, M. (2017). A primer on partial least squares structural equation modeling (PLS-SEM) (Second Edi). Sage publications.

Harelimana, J. B. (2018). Effect of Tax Audit on Revenue Collection in Rwanda. Global Journal of Management and Business Research, 18(2).

Henseler, J., Ringle, C. M., \& Sarstedt, M. (2014). A new criterion for assessing discriminant validity in variance-based structural equation modeling. Journal of the Academy of Marketing Science, 43(1), 115-135. 
https:// doi.org/10.1007/s11747-014-0403-8

Henseler, J., Ringle, C. M., \& Sinkovics, R. R. (2009). The use of partial least squares path modeling in international marketing. Advances in International Marketing, 20, 277-319. https://doi.org/10.1108/S14747979(2009)0000020014

Hidayat, R., \& Cheisviyanny, C. (2013). Pengaruh Kualitas Penetapan Pajak dan Tindakan Penagihan Aktif terhadap Pencairan Tunggakan Pajak. Jurnal WRA, 1(1), 1-20. Retrieved from http:/ / ejournal.unp.ac.id/index.php/wra/article/viewFile/2311/1929

Hulland, J. (1999). Strategic Management Journal. 1. Strategic Management Journal, 20(2), 195-204. Retrieved from http://www.jstor.org/stable/3094025

Irawan, F., \& Maharani, S. (2016). Perception Analysis on Tax Audit Quality Jawa Barat I Regional Tax Office (Analisis Persepsi Kualitas Pemeriksaan Pajak: Studi Kasus pada Kanwil DJP Jawa Barat I). Jurnal Ilmiah Akuntansi Universitas Pamulang, 4(2), 958-973. Retrieved from http://openjournal.unpam.ac.id/index.php/JIA/article/view/168

James Alm, Michael Mckee, C. B. (2004). Audit Selection and Firm Compliance with a Broad- based Sales Tax. (April 2019). https:// doi.org/10.2139/ssrn.897314

Ken Kwong-Kay Wong. (2013). Partial Least Squares Structural Equation Modelling (PLS-SEM) Techniques Using SmartPLS. Marketing Bulletin, 24. Retrieved from bulletin.massey.ac.nz/V24/MB_V24_T1_Wong.pdf

http:/ / marketing-

Khersiat, O. M. (2018). The Role of the Forensic Accountant in the Detection of Tax Fraud in Financial Statements: A Survey Study in the Jordanian Accounting and Auditing Offices and Firms. International Journal of Economics and Finance, 10(5), 145. https:// doi.org/10.5539/ijef.v10n5p145

Lestari, N., \& Nedya, S. (2019). The Effect of Audit Quality on Tax Avoidance. (January). https://doi.org/10.2991/icastss-19.2019.69

Mebratu, A. A. (2016). Impact of Tax Audit on Improving Taxpayers Compliance: Emperical Evidence from Ethiopian Revenue Authority at Federal Level. International Journal of Accounting Research, 2(12), 1-19. https:// doi.org/10.12816/0033279

Ministry of Fiscal Policy Agency, M. of F. of I. (2018). Tax Expenditure Report 2016$2017 . \quad$ Retrieved from http://www.fiskal.kemenkeu.go.id/publikasi/TER/ter2016-2017.pdf

Modugu, K. P., \& Anyaduba, J. O. (2014). Impact of tax audit on tax compliance in Nigeria. International Journal of Business and Social Science, 5(9), 207-215.

Murray, J., \& Thomson, M. E. (2009). An Application of Attribution Theory to Clinical Judgment. Europe's Journal of Psychology, 5(3). https:// doi.org/10.5964/ejop.v5i3.257

Nnyanzi, J. B., Bbale, J. M., \& Sendi, R. (2018). Financial Development and Tax Revenue: How Catalytic Are Political Development and Corruption? International Journal of Economics and Finance, 10(8), 92. https:// doi.org/10.5539/ijef.v10n8p92

Nunn, L., McGuire, B. L., Whitcomb, C., \& Jost, E. (2006). Forensic Accountants: Financial Investigators. Journal of Business \& Economics Research (JBER), 4(2), 1-6. https://doi.org/10.19030/jber.v4i2.2631 
OECD. (2000). Improving Access to Bank Information for Tax Purposes. Improving Access to Bank Information for Tax Purposes. https:/ / doi.org/10.1787/9789264181267-en

OECD. (2006). Strengthening Tax Audit Capabilities: General Principles and Approaches. Oecd, 54(October). Retrieved from https://www.oecd.org/tax/administration/37589900.pdf

Okon, B. (2018). Financial Sector Development and Tax Revenue in Nigeria. International Journal of Economics, Commerce and Management, VI(6), 93-109. Retrieved from http://ijecm.co.uk/wp-content/uploads/2018/06/667.pdf

Palil, M., \& Mustapha, A. F. (2011). Determinants of tax compliance in Asia: A case of Malaysia. European Journal of Social Sciences, 24, 7-32. Retrieved from https:// www.researchgate.net/publication/286587978_Determinants_of_ta x_compliance_in_Asia_A_case_of_Malaysia

Pemerintah Republik Indonesia, R. I. (2017). Peraturan Pemerintah Pengganti Undang-Undang Republik Indonesia Nomor 1 Tahun 2017 Tentang Akses Informasi Keuangan untuk Kepentingan Perpajakan. Retrieved from https:// www.ortax.org/ortax/?mod=aturan\&page=show\&id=16276

Putra, P. D., Syah, D. H., \& Sriwedari, T. (2018). Tax Avoidnce: Evidence of As a proof of Agency Theory and Tax Planning. International Journal of Research $\mathcal{E}$ Review, 5(9), 52-60. https:/ / doi.org/10.1107/s0108768109011057

Rahim, H. A., Topowijono, S. N. (2016). Analisis Efektivitas Pelaksanaan Pemeriksaan Pajak Atas Penerbitan Surat Ketetapan Pajak. Jurnal Perpajakan (JEJAK), 10(1), 1-8. Retrieved from http:// perpajakan.studentjournal.ub.ac.id/index.php/perpajakan/article/ view $/ 290$

Republik Indonesia, R. I. (2007). Penjelasan atas Undang-Undang Republik Indonesia Nomor 28 Tahun 2007 Tentang Perubahan Ketiga Atas Undang-Undang Nomor 6 Tahun 1983 Tentang Ketentuan Umum Dan Tata Cara Perpajakan. Retrieved from https:/ /jdih.kemenkeu.go.id/fulltext/2007/28Tahun2007UUPenj.pdf

Retnaningtyas Widuri, Devina, Fransiska Marta, Y. W. (2019). The Influence of Penalties, the Trust on Authorities, and the Tax Audit Toward Tax Compliance. 2(2), 218-229. https:// doi.org/10.31014/aior.1992.02.02.81

Rotich, C. C., Kiprop, S. K., \& Nzioki, P. M. (2019). The effect of audit case selection on tax audit effectiveness in south rift valley region, Kenya. 69-75. Retrieved from http://www.academicjournal.in/download/2394/4-6-27-475.pdf

Sari, E., \& Nugraha, E. (2018). Kebijakan Akses Informasi Keuangan Terhadap Perilaku Wajib Pajak dan Implikasinya Terhadap Tingkat Kepatuhan Wajib Pajak. TEKUN: Jurnal Telaah Akuntansi Dan Bisnis, 9. https:// doi.org/10.22441/tekun.v8i1.2599

Setia, H. (2015). Pengaruh Frekuensi Pemeriksaan Pajak dan Kualitas Pemeriksa Pajak Terhadap Tingkat Kepatuhan Wajib Pajak Badan. 17(1), 10-22. Retrieved from https://jurnaltsm.id/index.php/JBA/article/view/10 